\title{
Origens do desenvolvimento nacional ${ }^{*}$
}

André Azevedo da Fonseca**

GOMES, Ângela de Castro (org.), Minas e os fundamentos do Brasil moderno, Belo Horizonte, Editora UFMG, 2005.

Minas e os fundamentos do Brasil moderno é uma obra capitaneada pela Fundação Israel Pinheiro e integra o projeto "Os caminhos do Brasil moderno", um conjunto de ações promovidas pela própria entidade, que inclui também a edificação do Espaço Israel Pinheiro, na Praça dos Três Poderes, em Brasília, além da criação do Museu Casa de João Pinheiro, na cidade de Caeté (MG). Ou seja, este livro deve ser compreendido como uma obra integrada a uma série de iniciativas que procuram preservar uma dada memória do desenvolvimentismo no Brasil, tendo como foco central a contribuição de João Pinheiro e, mais tarde, de seu filho Israel Pinheiro na política brasileira.

Em síntese, os artigos procuram sustentar a concepção de que a gênese do projeto desenvolvimentista já estava configurada desde o início da República na figura do próprio João Pinheiro, presidente do Estado de Minas Gerais, e que tal ideário teria sido conduzido por seus filhos, parentes e políticos de um círculo de influências que incluiu, entre outros, Juscelino Kubitschek e Tancredo

* Resenha recebida em setembro de 2007 e aprovada para publicação em novembro de 2007.

** Doutorando em História Cultural pela UNESP/Franca. E-mail: azevedodafonseca@gmail. com. 
Neves. Para defender essa hipótese explicativa, o livro conta com um prefácio, uma apresentação, um texto de abertura e 10 capítulos divididos em três partes bem distintas - e bastante desiguais.

No prefácio, Israel Pinheiro Filho traça um breve histórico das idéias de Israel Pinheiro e reproduz duas entrevistas de João Pinheiro concedidas em 1906, quando o então presidente de Minas expressou a síntese de sua visão modernizadora e estabeleceu uma espécie de documento básico que fundamentaria seus seguidores políticos. Na apresentação, Ângela de Castro Gomes conta a história da própria obra e apresenta os capítulos do livro. Em seguida, o bibliófilo José Mindlin, no texto de abertura, expressa uma visão bastante pessoal sobre o papel de Minas e dos políticos mineiros na modernização do país.

A primeira parte do livro conta com os quatro capítulos propriamente historiográficos e sociológicos da obra: "Ouro, terra e ferro: vozes de Minas", de José Murilo de Carvalho; "Memória Política e tradição familiar: os $\mathrm{Pi}$ nheiro das Minas Gerais", de Ângela de Castro Gomes; "João Pinheiro e as origens do desenvolvimento mineiro", de Otávio Dulci; e "O Brasil de João Pinheiro: o projeto educacional”, de
Helena Bomeny. A segunda parte reúne os capítulos "A genealogia do nacional desenvolvimentismo brasileiro: João Pinheiro, Vargas, JK e Israel Pinheiro", de Vamireb Chacon; "O desenvolvimentismo de Israel Pinheiro e Juscelino Kubitschek", de Oscar Lorenzo Fernandez; e "O ISEB e a retomada do desenvolvimento nacional", de Hélio Jaguaribe. Com exceção do artigo de Chacon, os textos oferecem uma análise bem pessoal sobre os períodos em questão e não contam sequer com bibliografia de apoio. Por fim, na terceira parte, em artigos ainda mais pessoais, Cornélio Octávio Pinheiro Pimenta, neto de João Pinheiro, escreve "João Pinheiro, Israel Pinheiro e a busca da modernidade plena"; João Camilo Pena assina "Israel Pinheiro e o desenvolvimento de Minas Gerais"; e Eliezer Batista registra suas impressões em "Modernização: uma visão sistêmica e holística”. Essa última parte assume um tom eminentemente testemunhal e, por várias vezes, torna-se nitidamente apologético às figuras da família Pinheiro. Contudo, a organizadora defende que esses textos devem ser lidos como "depoimentos de atores que viveram as experiências e conviveram com os protagonistas das histórias que relatam".

1 Ângela de Castro Gomes, "Memória, política e tradição familiar: os Pinheiro das Minas Gerais", in Ângela de Castro Gomes (org.), Minas e os fundamentos do Brasil moderno, Belo Horizonte, Editora UFMG, 2005. 
Castro Gomes ${ }^{1}$ observa que a história política de Minas é, em grande medida, a história de grandes famílias que se alternavam nas tarefas de liderança do Estado. O sentimento de "orgulho da linhagem" foi uma das características marcantes do tipo de solidariedade que instituía a autoridade política nessa sociedade familista. Tendo em vista essas especificidades, a historiadora procura evidenciar que a permanência da memória da família Pinheiro na política mineira não é um fato espontâneo, mas contou com a ação de propagadores que souberam articular práticas culturais eficientes e, em um trabalho sistemático, buscaram associar o patriarca a uma representação de progresso que seria reinventada nas décadas seguintes nos ideários de modernização e desenvolvimento.

Dessa forma, Gomes mostra como uma série de procedimentos foi efetuada pelas novas gerações para sustentar o processo de "invenção de uma tradição política” baseada em princípios fundadores que deveriam ser conhecidos, mantidos, defendidos e reinventados no decorrer da história. Além da transmissão oral da memória de João Pinheiro em regulares colóquios familiares e partidários, nota-se também uma tradição de discursos políticos repletos de referências aos textos deixados pelo patriarca, sobretudo pronunciamentos e entrevistas na imprensa, que eram sempre lidos e mencionados pelos seguidores. Mas quais eram as idéias políticas expressas no chamado "Evangelho Republicano Segundo João Pinheiro"?

José Murilo de Carvalho, com aquela liberdade de escrita unida a um rigor de pesquisa que o caracteriza, procura sistematizar a história social de Minas em três vozes: uma caracterizada pela economia do ouro, da Minas "urbana, caótica, rebelde"; outra dominada pela economia agrícola e pecuária - a "voz da terra", marcada por um caráter conservador, ordeiro, equilibrado e familístico; e, por fim, a "voz do ferro", do estado sacudido pelas grandes siderúrgicas e pelas cidades industriais. ${ }^{2}$ Carvalho atribui à Escola de Minas de Ouro Preto, criada em 1876, a introdução no país do que viria mais tarde a ser conhecida como "mentalidade desenvolvimentista". Na contramão do espírito bacharelesco do sistema educacional do império, essa instituição voltada para as aplicações práticas formou uma geração de homens que, mais tarde, se dedicando à criação de indús-

\footnotetext{
${ }^{2}$ José Murilo de Carvalho. "Ouro, terra e ferro: vozes de Minas", in Ângela de Castro Gomes (org.), Minas e os fundamentos do Brasil moderno, Belo Horizonte, Editora UFMG, 2005, p. 56
} 
trias e espalhando-se pela burocracia estatal, influenciou o incremento da exploração de minérios e estabeleceu os rumos da política industrial no Estado na primeira metade do século XX. Um dos alunos dessa escola foi João Pinheiro, que na maturidade política passaria a defender um projeto de desenvolvimento econômico liderado pelo Estado.

Nascido em 1860, na cidade do Serro (MG), João Pinheiro cursou a Faculdade de Direito de São Paulo e tornou-se antimonarquista histórico quando, em 1887, organizou o movimento republicano mineiro, lançando o jornal Movimento. Após a Proclamação da República, tornou-se secretário do governo estadual e, em 1890, foi nomeado governador - cargo em que permaneceu por poucos meses, tendo em vista as divergências com o governo federal. Neste ano, Pinheiro elegeu-se deputado constituinte e permaneceu no congresso até 1893 , quando preferiu dedicar-se a atividades industriais, fundando a Cerâmica de Caeté. Em 1889 foi ainda vereador e agente executivo dessa cidade. Seu retorno à presidência de Minas, em 1906, seria precedido por sua atuação no Congresso Agrícola, Industrial e Comercial, considerado por muitos um marco na história do desenvolvimento de Minas.

Como mostra Otávio Dulci, a experiência industrial de João Pinheiro ampliara sua percepção sobre questões econômicas e fundamentara a perspectiva "desenvolvimentista" que marcaria sua volta à vida pública estadual. Dulci pondera que, evidentemente, o conceito de "desenvolvimento econômico" não era corrente no final do século XIX. Na verdade, falava-se genericamente em "progresso". Mas o historiador argumenta que, na prática, o interesse básico de João Pinheiro recaía sobre "o processo de desenvolvimento" nos termos em que viria a ser compreendido por cientistas sociais no decorrer do século XX. Para Dulci, o termo desenvolvimento, no campo socioeconômico, é "uma idéia referente à superação intencional de uma situação de atraso relativo". Envolve, por isso, uma clara dimensão política, que se traduz em ações governamentais e na mobilização de grupos diversos em torno da meta de superação da estagnação. "Podemos chamar de desenvolvimentismo ao pensamento que focaliza esse processo numa perspectiva de projeto, realçando seu sentido estratégico e seu potencial mobilizador."

\footnotetext{
${ }^{3}$ Otávio Dulci, "João Pinheiro e as origens do desenvolvimento mineiro", in Ângela de Castro Gomes (org.), Minas e os fundamentos do Brasil moderno, Belo Horizonte, Editora UFMG, 2005 , p. 114.
} 
Nessa perspectiva, a questão do desenvolvimento parece ter surgido precocemente na agenda pública mineira devido a uma consciência cada vez mais nítida do retrocesso relativo da economia regional, associada a uma percepção de que a situação deveria ser tratada como uma questão política. Dulci mostra como o problema da superação do atraso tornou-se uma preocupação recorrente dos poderes públicos e das elites mineiras desde fins do século XIX. Algumas vezes, a imagem da estagnação surgia por contraste com a idealização de um passado de riqueza e prestígio do ciclo do ouro, mas também aparecia através de comparações desfavoráveis com o avanço econômico de outras áreas do país - particularmente São Paulo. Nesse contexto, surgiu no debate político a insistência nas "potencialidades inexploradas da região" e a ênfase na idéia de "recuperação econômica". Unida a esse diagnóstico, tornava-se corrente a imagem de um estado desarticulado e disperso, feito um mosaico de zonas diferenciadas entre si e, por isso, de difícil governo.

A principal iniciativa tomada por efeito dessas primeiras políticas de desenvolvimento foi, sem dúvida, a transferência da capital, em 1897, de Ouro Preto para Belo Horizonte. Essa idéia circulava desde o Império, mas somente no início da República foi estabelecido um acordo geral em torno da conveniência de erigir um centro político moderno que "simbolizasse o começo de uma nova fase de progresso". Para Dulci, tendo em vista que a questão da mudança da capital fora um plano decidido e executado na órbita estatal, representando uma ousada iniciativa de planejamento público que, em certo sentido, se afastava significativamente da ortodoxia liberal em voga, este deve ser compreendido como um projeto nitidamente associado a metas desenvolvimentistas. "Esperava-se que a nova capital viesse efetivamente a exercer o papel de centro de integração política e econômica do 'mosaico mineiro'. E, além disso, esperava-se que a iniciativa da mudança contribuísse firmemente para colocar Minas Gerais na trilha do progresso."

Em maio de 1903, após 10 anos longe da política estadual, João Pinheiro liderou o Congresso Agrícola, Industrial e Comercial, um evento que se manteve como um ponto de referência da modernização de Minas até meados do século XX. Com o objetivo de debater o atraso mineiro e definir caminhos para a "restauração econômica" do estado, o congresso discutiu a questão da diversificação econômica, traduzida sobretudo pelo estímulo à policultura como uma me- 
dida para combater a vulnerabilidade da economia brasileira devido à extrema dependência das exportações de café. Assim, para Minas, a "restauração econômica" passava pelo estímulo à diversificação produtiva com o objetivo de favorecer o mercado interno. Para João Pinheiro, as propostas voltadas para a reconstrução econômica de Minas giravam em torno de prêmios e estímulos pecuniários para a iniciativa privada; de auxílio para o estabelecimento de cooperativas de produção, crédito e circulação; além de algumas medidas protecionistas. Como notou Dulci, observa-se neste conjunto de orientações um distanciamento crítico perante a orientação econômica do liberalismo clássico. "Esta não é negada, mas filtrada: os princípios do livre comércio são aceitos em tese, mas deveriam ser adaptados às necessidades de 'países novos' como o Brasil.” Essas diretrizes foram imediatamente implantadas no governo Francisco Sales em 1903, em uma espécie de "pacote econômico" que oficializou a política de diversificação produtiva. Mas é interessante observar o impacto nacional da reunião, pois as conclusões do congresso não se restringiram a pensar a economia regional, mas direcionaram-se no sentido de formular medidas globais para a economia nacional. E essa repercussão favoreceu sobremaneira a estratégia da cúpula mineira para ganhar espaço político no cenário nacional. "Na esteira desse movimento, ela alcançaria pela primeira vez a presidência da república, com a candidatura de Afonso Pena, interrompendo doze anos de hegemonia paulista."

A questão do ensino técnico também ganhou importância a partir desse evento. O ponto crucial estava na problemática da força de trabalho - uma inquietação dos proprietários que, acostumados ao regime escravocrata, temiam a evasão de trabalhadores, a irregularidade da oferta de trabalho, a falta de disciplina e a carência de qualificação da mão-deobra disponível. Por conseguinte, o ensino agrícola foi concebido como uma forma de adestrar a força de trabalho e fixar o trabalhador rural ao solo. O positivista João Pinheiro foi o principal idealizador dessa política. Ele defendia que o Estado tinha uma "missão pedagógica, de educar a população para o progresso". Isso fez com que empreendesse um esforço no sentido de expandir o ensino primário e de criar estabelecimentos de aprendizagem agrícola, traduzida em "fazendas-modelo e campos de experiência e demonstração, que se somavam ao serviço de instrutores ambulantes na divulgação de novas técnicas e do uso da mecanização". 
João Pinheiro candidatou-se ao Senado em fins de 1904 e só deixou o cargo em 1906 quando assumiu o governo de Minas. Em sua campanha à presidência do estado, Pinheiro divulgara um programa detalhado de ação, enfatizando, sobretudo, temas econômicos. Diferentemente dos republicanos que se preocupavam prioritariamente com a "organização legal” da federação, Pinheiro direcionou esforços para a "organização econômica” do estado. Segundo Dulci, são freqüentes as referências de Pinheiro sobre a necessidade de substituir a "política partidária" pela "política econômica".

Dessa forma, o evangelho republicano segundo João Pinheiro defendia a proteção à indústria "enquanto esta não se acha bastante forte para lutar com vantagens com as indústrias estrangeiras" e a reorganização do trabalho agrícola (onde estava alocada a grande massa dos trabalhadores) através de medidas voltadas para estimular empregos no campo e promover educação profissional. Como mostra Bomeny, ${ }^{4}$ o programa educacional do governo Pinheiro marcou-se pela ênfase nos aspectos práticos que de- veriam ser incorporados à formação do trabalhador. Entre as medidas para efetuar-se essa "reforma agrícola" estavam a criação de colôniasmodelo instituídas pelo estado, além de políticas de exploração mineral que incluíam "divisão da propriedade agrícola" através de, entre outros procedimentos, a "desapropriação por utilidade pública".

Os textos de Fernandez, Jaguaribe, Pimenta, Penna e Batista, como vimos, têm um caráter bastante pessoal e ganham mais sentido quando os relacionamos com as reflexões da obra como um todo.

Em suma, feita a ressalva perante uma clara intenção de enaltecimento da figura de João Pessoa, Minas e os fundamentos do Brasil moderno contribui bastante para a reflexão sobre a política econômica brasileira republicana e para a discussão das prováveis raízes do ideário desenvolvimentismo. Como escreveu Chacon, movimentos sociais e épocas históricas "somente depois são denominados; antes, vão sendo preparados e, durante seu desempenho, se desenrolam e se consomem, deixando sementes e inspirações para o futuro". ${ }^{5}$

\footnotetext{
${ }^{4}$ Helena Bomeny, "O Brasil de João Pinheiro: o projeto educacional", in Ângela de Castro Gomes (org.), Minas e os fundamentos do Brasil moderno, Belo Horizonte, Editora UFMG, 2005, p. 137-166

${ }^{5}$ Vamireh Chacon, "A genealogia do nacional-desenvolvimentismo brasileiro: João Pinheiro, Vargas, JK e Israel Pinheiro", in: Ângela de Castro Gomes (org.), Minas e os fundamentos do Brasil moderno, Belo Horizonte, Editora UFMG, 2005, p. 193.
} 
Para compreender o desenvolvimen- desencadeado este processo. E nesse tismo dos anos 1950, portanto, se faz sentido, a obra oferece um conjunto necessário investigar as complexas e bastante rico de reflexões. distantes conjunturas que podem ter 